\title{
Inclusive Democracy in Nigeria: The Roles of the Indigenous Languages
}

\author{
Eucharia Okwudilichukwu Ugwu,
}

Department of Arts and Social Sciences Education, University Of Ibadan, Ibadan, Nigeria

Doi:10.19044/esj.2020.v16n17p48～URL:http://dx.doi.org/10.19044/esj.2020.v16n17p48

\begin{abstract}
Language is like a chord that binds people together. However, when language issues are not properly handled, they can cause exclusion and division, especially in highly multilingual societies like Nigeria. Thus, language rights are now recognised globally as aspects of human rights. As a dominant and official language in Nigeria, English has tended to exclude many citizens from full participation in developmental activities and life opportunities due to limited access to it. This is irrespective of the fact that one major justification for its promotion, as against the indigenous languages, hinges on the rhetoric of national unity. Unity can hardly be achieved in an atmosphere of marginalisation and widening inequality gap. Given the multilingual and multi-ethnic status of Nigeria, respecting the language rights of the different ethnolinguistic communities is indispensable for mutual and peaceful co-existence and enhanced quality of life. This paper highlights the important roles the indigenous languages could play in making Nigeria a truly plurilingual nation bound by respect for human lives and values, equity and tolerance.
\end{abstract}

Keywords: Nigerian indigenous languages, language right, human rights, language diversity, language and exclusion

\section{Introduction}

Nigeria is one of the most linguistically heterogeneous countries of the world with a diversity index of 0.866 (Simons \& Charles, 2018). Citing Lieberson (1981), the authors define diversity index as the probability that any two people of the country selected at random would have different mother tongues. The index is rated from 1-0 (highest to lowest possible values). The value, 'one', indicates total diversity (that is to say, no two people in the country have the same mother tongue). The closer a country is to one (1), the higher her diversity index. Conversely, zero indicates no diversity at all, that 
is to say, everyone in the country has the same mother tongue). Thus, by being closer to $1,(0.866)$, Nigeria has a high diversity index. Some geo-political units in Nigeria have more languages than the others. In the south-east (Abia, Anambra, Ebonyi, Enugu and Imo) for example, Igbo is the predominant language just as Yoruba predominates in the south-west (Ekiti, Lagos, Osun, Ondo, Ogun and Oyo). However, in the south-south, Cross River State alone has up to 37 languages with a network of dialects and language clusters (Ugot \& Ogar, 2014)

Language is a marker of ethnic identity as well as the mediator of cultural, symbolic and material resources (Lo Bianco, 2013). Every language, according to UNESCO (2003) "is a unique expression of the human experience of the world", thus, "the knowledge of any single language may be the key to answering fundamental questions of the future" (p. 2). Mitchell and Miller (2019) observe that "collective and individual identity, dignity, and power are bound up in the social stature of a group's "mother tongue" (p. 236). Thus, every language has an inherent value which neither depends on the status a state or the society assigns to it, nor on the number of its speaker. Skutnabb-Kangas (2002) sees linguistic and cultural diversity as an added advantage to the society. Citizens of such countries, the author believes, have access to more varied knowledges, ideas, and cosmo-visions than those in countries with few languages and cultures. If that is true, then Nigeria must begin to consider her multilingual status as a source of cultural enrichment that must be maintained and preserved. Her rich linguistic resources need to be harnessed for knowledge economy and development. Unfortunately, many Nigerian languages are presently threatened with extinction due to their utter neglect by both the government and the society at large.

There is hardly any area of the national life that has no link to the effective use of languages for communication, especially the local languages. This includes quality and equality of access to education, participatory democracy, social cohesion and people-centred development. The delegates to the Intergovernmental Conference of Ministers on Language Policies in Africa rightly acknowledge that "language issue cuts across all sectors of national life" (Harare Declaration 1997, p. 4). Moreover, language right is now seen as an inalienable aspect of human rights. Ndhlovu (2008) points to the "post-modernist human rights discourses" in which the multiplicity of languages is seen "within the context of democracy and human rights, whereby the right to language(s) of choice is considered an integral part of fundamental human rights" (p. 138).

As a highly multilingual and ethnic country, Nigeria needs to uphold the dual status to ensure that the rights of her citizens are respected and to guarantee democracy. This paper discusses the roles of the indigenous languages in guaranteeing inclusive democracy in Nigeria. 


\section{Language, Nigeria's Rich Endowments}

Ability to utilise language for various functions is one of the key attributes of human beings. However, the roles of language extend from the individuals to the society at large. Without a common language, human development, globalisation and social cohesion would be a mirage. Ugwu and Ogunremi (2019) enumerate some of the key roles that language plays in the society, including a tool for critical and creative thinking, decision making, planning as well as the acquisition and sharing of knowledge, all of which help to make life better (p. 52). Language is a vehicle of value systems and cultural expressions, a unifying ethnic identity marker that gives one a sense of belonging; it guarantees human dignity, and is therefore, critical to the fulfilment of individual potential (Moseley 2010; Mitchell and Miller, 2019; International Conference on Languages, 2014; Global Education Monitoring Report, 2016a). Kua and Ismail (2017) further argue that language is not only a vital instrument of communication but also carries a dignity and intrinsic values central to increasing the resilience of vulnerable communities (p. 10). Thus, promoting linguistic pluralism in multilingual societies such as Nigeria is vital for human development and survival.

All languages, observes Marti (2010), are used to create symbolic worlds, to advance science, to pursue the arts of word and thought, to express values and hopes, and to accompany the mysteries of life and death (p. 259). However, a language that can serve these varied purposes in a given speech community may not be able to do the same in another speech community. In other words, while every language has inherent values and usefulness, the roles are relative to where they are spoken. For example, although languages such as English and French are recognised as world languages, they may not be able to fulfil the simplest linguistic needs (such as daily communication) among a particular rural community in Nigeria who do not know a word in either of these languages. Given this reality, it becomes unjust and unfair to impose a particular language on a group of people and suppress their own native language for whatever reason. While one language may guarantee more economic advantage over another by virtue of it being used in the global market or as a national language, this does not undermine the fact that the latter may be playing more central roles in the lives of the rural population who speak it than the former because the values of a language are not limited to financial gains. It is therefore, absolutely important to respect the linguistic rights of Nigerians by upholding pluralism.

Article 22 of the African Charter on Human Rights (1981) states that "all people shall have the right to their economic, social and cultural development with due regard to their freedom and identity and in the equal enjoyment of the common heritage of mankind" (p. 4). Recognising the 
linguistic minorities' rights in Nigeria includes ensuring that their languages remain relevant within the larger society. Some of the ways through which their relevance could be sustained include standardising and empowering them for functional literacy. Moseley (2010) is of the opinion that for African countries to maintain and perpetuate her linguistic diversity, speakers must find valid economic and cultural reasons for keeping their ancestral languages as vital media in natural everyday communication with their offspring. If the speakers of any language cease to see its relevance, they would shift to other languages that seem to guarantee better opportunities. However, if the languages remain relevant, their speakers may rather choose to be bilingual or multilingual without entirely shifting to the dominant ones and abandoning their own. According to Romaine (2015), "while the minority groups desire to acquire dominant languages as a means of accessing economic and other resources associated with them", they also "want to preserve some cultural autonomy for themselves and to have some say in determining their own fate, in particular, the right to educate their children" (p. 38).

In a recent study by Ezeokoli and Ugwu (2019), the scholars reported that parents, teachers and students see great potentials in the Nigeria indigenous languages. These stakeholders believe that the indigenous languages have both pedagogical and cultural values that need to be harnessed to make the educational system and the society better by teaching them in the secondary schools. Due to the multiplicity of languages in Nigeria, attaining a multilingual education will not be easy. However, there has to be a starting point, such as insisting on mother tongue education at the lower primary school - as contained in the National Policy on Education.

Club de Madrid (2009) emphasizes that "if individuals and peoples are not able to express themselves in their language, enjoy their culture and traditions, and pursue their aspirations, they will not live freely nor fulfil their dreams" (p. 13). Mitchell and Miller (2019) believe that to experience public life in one's own language is dignifying and could foster one's identification with both the state and fellow citizens (p. 237). However, in highly multilingual settings such as Nigeria, some languages are left behind due to lack of official recognition, not using them in the schools and their low status over the years. These factors are contributing to forcing their speakers to gradually abandon them and to embracing more cosmopolitan languages (Adewale \& Oshodi, 2013; Agantiem, 2017; Haruna, 2017). While language shift has become a common phenomenon in Nigeria as in different parts the world (Moseley, 2010; Simons \& Lewis, 2013; Ugwu, 2019a), effort must be made to discourage it, especially where such shift is rooted in discrimination or coercion - direct or indirect. If speakers of minority languages in Nigeria continue to shift to the major ones, many indigenous languages will go into extinction in the near future. The more the languages are lost, the more the 
rich cultural heritages embedded in them are also lost. If language right is however, considered as an aspect of human rights, then there will be no option than to make serious effort to ensure that speakers are not pushed to abandon their ancestral languages for whatever reasons.

\section{Language, Inclusion and Participatory Democracy}

Guaranteeing democracy is essential for the development and continued existence of any nation. Thus, the first overall philosophy of Nigerian education is "to live in unity and harmony as one indivisible, indissoluble, democratic and sovereign nation founded on the principles of freedom, equality and justice" (Federal Republic of Nigeria, 2014, 1). However, participatory democracy entails making every citizen count and this is enhanced if there is a free flow of information between the government and the governed. For this to become feasible in Nigeria, recognising the indigenous languages by upholding linguistic pluralism is indispensable. Upholding linguistic pluralism in Nigeria is fundamental to achieving the democratic principles while democracy is itself a tool for guaranteeing linguistic pluralism. The Asmara Declaration $(2000,2)$ sees the link between democracy and the development of African languages. The document notes that democracy is essential for the equal development of African languages and African languages are vital for the development of democracy based on equality and social justice.

The power of language in ensuring participatory democracy should not be underestimated. Equality and fairness, observed Club de Madrid (2009) are essential principles in building shared societies and they cannot exist where there is discrimination, marginalisation and lack of opportunity for all (p. 14). When a people's language is not recognised by the government, the speakers are invariably denied of the right to participate fully in the national life, including in politics, legal system, education and even the ability to function optimally in the modern world - in so far as they are unable to articulate themselves in the preferred language of governance. Besides, social justice demands a fair hearing especially when there is a conflict. Language is a vehicle for the delivery of justice but as Bamgbose (2011) explains, lack of a mutually-understood language could hinder the administration of justice and could also lead to health hazards. According to the author,

In a system of justice in which a litigant or an accused has to be subjected to questioning through an interpreter, it is not unusual to discover that there is often miscarriage of justice arising from faulty interpretation. Similarly, information on health which is not presented in a language that the consumer understands can lead to failure or even disastrous consequences. (p. 8). 
Igboanusi (2017) adds that "the provision of vital information to communities in languages they understand will help to prevent potential disasters which will in turn promote intense poverty among the people" (p. 18). The Global Education Monitoring Report (2016a) considers language, ethnicity and poverty as interactive factors that could produce an extremely high risk of being left far behind (p. 3).

Language unites, but also can also divide people; it can be a source of both inclusion and exclusion. In Nigeria, English language, for example, has tended to exclude many citizens from participating in the national life, even though one of the arguments in support of its choice as the national language hinges on national unity. As a second language that is mainly learned within the settings of formal education, adequate learning of English is mainly open to those Nigerians who have access to quality education. As at 2010, only $57.9 \%$ of the adult population and $76.9 \%$ of the youths in Nigeria were literate in English (National Bureau of Statistics, 2010, p. 8). Since English language is the preferred language of education and the indigenous languages are not welcomed in schools, literacy, in the Nigerian sense, is inseparable from proficiency in English. Thus, many illiterate Nigerians are excluded from governance and life's opportunities.

Club de Madrid (2009) identifies four essential ingredients that could make individuals or groups feel that they have a place in a society: the opportunity for democratic participation, respect for diversity and the dignity of the individual, equality of opportunity for all (to economic and material resources) and protection from discrimination (p. 30). As a multilingual nation, Nigeria can only guarantee these by maintaining a pluralistic society, by giving all her indigenous languages the opportunities to thrive rather than focusing mainly on the learning of English language. Galante (2018) insists that "learning one language as an attempt to blend in is not compatible with a society that is increasingly diverse" (p. 8). If English is indeed promoted in Nigeria for the sake of national unity as is often claimed, it must not be forgotten that there are millions of Nigerians who cannot functions in it. These groups are perpetually silenced, so far the languages they speak are silenced. There cannot be a true democracy where are a segment of the society is left speechless due to their inability to function in the preferred official language. To marginalise any language, insists (Ugwu, 2017), is to marginalise its speakers and the state of any language could be a reflection of the state of its speakers. The more vibrant the indigenous languages are made to be in Nigeria, the more vibrant their speakers might be because they would be empowered to think deeper and get involved in national and communal issues that could be life-changing. On the contrary, marginalisation can lead to a sense of alienation, lack of trust in the government, demand for equal rights 
and opportunities, and at the long run, political instability. The impact of linguistic marginalisation can be so great.

\section{Conclusion and Recommendation}

The journey to a democratic and an egalitarian society is not an easy one. While the Nigerian governments continue to pursue policies that would move the country forward in the areas of science, technology and material development, they should never forget that such efforts can only yield the desired results if all the citizens are carried along. Inclusion is both a necessity for and a means of achieving development. However, language right is central to inclusion. Any policy that makes a segment of the society feel a sense of alienation cannot be anything but unwholesome. Since Nigeria is a highly multilingual nation, it is important that the government recognises the roles of the indigenous languages both in human and material development. These languages need to be promoted so that those who speak them, whether they are few or many, would feel at home in the country, contribute their quotas to national development and live the life that they desire. Moreover, education is an indispensable tool for inclusion, economic advancement and cultural preservation but only to the extent that it encourages equal opportunity for all.

There is a need for the Nigerian government to standardise and increase the status of the numerous indigenous languages because this would help to uplift the speakers and give them both a voice and a place in the everincreasing competitive society. In view of that, using and promoting most of these languages in key areas, especially in education and the media are paramount to increasing their status, usability and sustainability. Since many languages are involved, it is obvious that all of them cannot receive attention at the same time. That would definitely be unthinkable. However, what is important is that there is a need to start somewhere. A starting point might be to start implementing the existing language policy on education and from there, to extend the use of the indigenous languages beyond the lower primary school.

\section{References:}

1. Adewale, R. K. \& Oshodi, B. (2013). Language endangerment in Nigeria: Focus on small ethnolinguistic communities in Niger state. Dialectologia, 11, 17-45

2. African Charter on Human and Peoples Rights (1981). Retrieved from http://www.humanrights.se/wpcontent/uploads/2012/01/African-Charter-on-Human-and-PeoplesRights.pdf 
3. Agantiem, A. A. (2017). Language (in) equality, language endangerment and the threats to Nigerian languages. Journal of Literature, Languages and Linguistics, 37, 21-28. www.iiste.org

4. Bamgbose, A. (2011). African Languages Today: The Challenge of and Prospects for Empowerment under Globalization. Retrieved from http://.lingref.com/cpp/acal/40/paper2561.pdf

5. Club de Madrid (2009). A Call to Action for Leadership to Build Shared Societies. Retrieved from www.clubmadrid.org

6. Ezeokoli, F. O. and Ugwu, E. O. (2019). Parents', Teachers' and Students' Beliefs about the Use and Study of Mother-tongue in the Secondary Schools in Akinyele Local Government Area, Oyo State, Nigeria. International Journal of Education \& Literacy Studies, IJELS 7(2):82-93. http://dx.doi.org/10.7575/aiac.ijels.v.7n.2p.82

7. Federal Republic of Nigeria. (2014). National Policy on Education. ( $5^{\text {th }}$ Ed.).

8. Galante, A. (2018). Language for Social Cohesion: Toward Plurilingualism and Pluriculturalism in Language Education.

9. Global Education Monitoring Report (2016a). If you don't Understand, how can you Learn? Policy Paper 24. Retrieved from http://unesdoc.unesco.org/images/0024/002437/243713E.pdf

10. Harare Declaration. (1997). Intergovernmental Conference of Ministers on Language Policy in Africa.

11. Haruna, H. H. (2017). Linguistic diversity and language endangerment: Towards the revitalisation of Bole language in Nigeria. International Journal for Innovative Research In Multidisciplinary Field, 3(10), 108-113.

12. Igboanusi, H. (2017). The Conflicts and Politics of Language. An inaugural Lecture 2016/2017. Ibadan University Press.

13. International Conference on Languages. (2014). Conclusions of the international conference on language, Suzhou, China. Retrieved from http://www.unesco.org/new/fileadmin

/MULTIMEDIA/HQ/ED/ED_new/pdf/Suzhou-conclusions-0611.pdf

14. Kua, E. and Ismail, M. B. (2017). Mother language as a powerful motivator for refugee education. In J. P. Marinotti, 2017 Symposium on Language, the Sustainable Development Goals, and Vulnerable Populations. Final Report. Retrieved from https://www.languageandtheun.org/symposium2017report.html

15. Lo Bianco, J. (2013). Language and Social Cohesion: Malaysia, Myanmar, Thailand. Final Desk Review. Retrieved from https://www.researchgate.net/publication /285581076_Language_and_Social_Cohesion_Malaysia_Myanmar_ Thailand_Final_Desk_Review 
16. Marti, F. (2010). Linguistic Diversity, Violence and Peace. Retrieved from

https://www.academia.edu/21116697/The_Management_of_Linguisti c_Diversity_and_Peace_Processes

17. Mitchell, D. and Miller, M. (2019).Reconciliation through language learning? A case study of the Turas Irish language project in East Belfast. Ethnic and Racial Studies, 42:2, 235-253, DOI: 10.1080/01419870.2017.1414278

18. Moseley, C. (ed.). (2010). Atlas of the World's Languages in Danger, 3rd edition. Paris: UNESCO Publishing. Retrieved from www.unesco.org/culture/en/endangeredlanguages

19. National Bureau of Statistics (2010). Report of the National Literacy Survey. Retrieved from www.nigerianstat.gov.ng

20. Ndhlovu, F. (2008). Language and African Development: Theoretical Reflections on the Place of Languages in African Studies. Nordic Journal of African Studies 17(2): 137-151.

21. Romaine, S. (2015). The Global Extinction of Languages and Its Consequences for Cultural Diversity. http://www.springer.com/9783-319-10454-6

22. Simons, G. F. \& Charles. D. F. (eds.). (2018). Ethnologue: Languages of the World. (21 $1^{\text {st }}$ ed.). Texas: SIL International. http://www.ethnologue.com

23. Simons, G. F. \& Lewis, M. P. (2013). The World's Languages in Crisis: A 20-year Update. Retrieved from

http://www01.sil.org/ simonsg/preprint/Wisconsin\%20Symposium.p df

24. Skutnabb-Kangas, T. (2002). Why should linguistic diversity be maintained and supported in Europe? Some arguments. Retrieved from http://www.coe.int/T/DG4/Linguistic/Source/SkutnabbKangasEN.pdf

25. The Asmara Declaration on African Languages and Literatures. (2000). Retrieved from https://www0.sun.ac.za/taalsentrum/assets/files/Asmara\%20Declarati on.pdf

26. Ugot, M. and Ogar, M. N. (2014). Language and Power in Cross River State, Nigeria. Mediterranean Journal of Social Sciences. 5(10), 648656.

27. Ugwu, E. O. (2017). Promoting Nigerian languages beyond the $21^{\text {st }}$ century: problems and Prospect. In D. O. Fakeye, S. A. O. Oladunjoye, I. A. Alade, B. O. Kayode- Olawoyin, O. R. Bateye, S. O., Olatunji, and O. S. Jayeoba (Eds.). Further thoughts on language, education, 
and the curriculum nexus for sustainable development in Nigeria. Ibadan: Constellation Books. 107-145.

28. Ugwu, E. O. (2019a). Africa on the Verge of a Linguistic Genocide: The Need for Action. European Scientific Journal, 15(23). Doi:10.19044/esj.2019.v15n23p57

29. Ugwu, E. O. and Ogunremi, P. O. (2019). Nigeria and the Sustainable Development Goals: Why the indigenous languages count. European Scientific Journal, 15(5), 52-68. Doi:10.19044/esj.2019.v15n5p5

30. UNESCO. (2003). Language Vitality and Endangerment. Retrieved from

http://www.unesco.org/new/fileadmin/MULTIMEDIA/HQ/CLT/pdf/ Language_vitality_and_endangerment_EN.pdfs

31. UNESCO Bangkok (2012). Why language matters for the Millennium Development Goals. Retrieved from http://unesdoc.unesco.org/images/0021/002152/215296e.pdf

32. United Nations. 2008. Report of the international expert group meeting on indigenous languages. Retrieved from https://documentsddsny.un.org/doc/UNDOC/GEN/N08 $/ 213$ 156/PDF/N0821356.pdf?OpenElement

33. Wurm, S. A. (Ed.) (2001): Atlas of the World's Languages in Danger of Disappearing, Paris, UNESCO Publishing. ( $2^{\text {nd }}$ Ed.). Retrieved from http://unesdoc.unesco.org/images/0012/001236/123609e.pdf 